\title{
Práticas de gestão da informação e inovação aberta em um pólo tecnológico brasileiro
}

\author{
Ana Clara Cândido \\ Mariene Alves do Vale
}

\begin{abstract}
IUniversidade Federal de Santa Catarina, Programa de Pós-Graduação em Ciência da Informação, Florianópolis, SC, Brasil. Universidade Nova de Lisboa, Centro Interdisciplinar de Ciências Sociais, Lisboa, Portugal.

Doutora em Avaliação de Tecnologia - Universidade Nova de Lisboa. Professora no Programa de Pós Graduação em Ciência da Informação - PGCIn da Universidade Federal de Santa Catarina. Pesquisadora Associada no Centro Interidisciplinar de Ciências Sociais da Universidade Nova de Lisboa (CICS.NOVA).

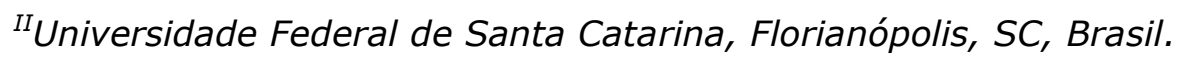
Especialista em Gestão Estratégica de Negócios pela Faculdade de Ciências Econômicas da Universidade Federal de Minas Gerais. Cursa bacharelado em Ciência da Informação na Universidade Federal de Santa Catarina.
\end{abstract}

http://dx.doi.org/10.1590/1981-5344/3614

As inovações de produtos e serviços eram desenvolvidas, sobretudo, internamente nas organizações até a propagação do modelo de Inovação Aberta no ambiente de negócios. Os processos colaborativos de inovação acontecem a partir da interação entre atores distintos: fornecedores, clientes, instituições de ensino e pesquisa e o governo. Nesse cenário, a informação precisa ser tratada adequadamente por meio da gestão estratégica da informação. Dos procedimentos metodológicos, tratase de um estudo exploratório e descritivo, qualiquantitativo que buscou conhecer como as empresas do polo tecnológico de Florianópolis gerem a informação e realizam suas práticas de inovação. Os resultados evidenciam a ausência de setores e profissionais dedicados exclusivamente à gestão da informação. As principais fontes de informação são as mídias digitais e os eventos promovidos por entidades representativas. Existem procedimentos padronizados, porém não formalizados, para organizar, armazenar, distribuir e utilizar a informação. A inovação, maioritariamente, é resultado da contribuição dos próprios colaboradores, 
assim como dos consumidores finais e dos fornecedores. O principal motivador para o investimento em inovação é a necessidade de manter-se à frente dos concorrentes, além da redução de custos e o aumento do valor percebido pelos clientes, também contribuindo para o aprendizado dos profissionais envolvidos.

Palavras chave: Gestão da Informação. Inovação Aberta. Polo tecnológico.

\section{Information management and open innovation practices in a brazilian technological center}

Innovation product and service were developed, mainly, internally in the organizations until the propagation of the model of Open Innovation in the business environment. Collaborative innovation processes take place through the interaction between different actors: suppliers, consumers, education and research institutions and the government. Information needs to be adequately addressed through strategic information management. From the methodological procedures, it is an exploratory and descriptive, qualitative-quantitative study that sought to know how the companies of the technological pole of Florianópolis manage the information and carry out their innovation practices. The results highlight the absence of sectors and professionals dedicated exclusively to information management. The main sources of information are digital media and events promoted by representative entities. There are standardized, but not formalized, procedures for organizing, storing, distributing and using information. Most of the innovation is the result of contributions from employees themselves, as well as from final consumers and suppliers. The main motivator for investment in innovation is the need to stay ahead of competitors, in addition to reducing costs and increasing the value perceived by customers, also contributing to the learning of the professionals involved.

Keywords: Information Management; Open Innovation; Technological center.

Recebido em 28.07.2018 Aceito em 21.12.2018 


\section{Introdução}

Os avanços tecnológicos das últimas décadas impulsionaram diversos estudos na área de gestão e estratégia, enfatizando o papel das organizações e os fatores que contribuem para a competitividade. A alteração na percepção sobre a importância dos recursos das organizações como fonte de valor agregado é uma característica deste movimento.

Neste ponto, a economia migrou de uma produção baseada em bens, na qual o trabalho e o capital eram fatores chave, para uma economia baseada em serviços, intensiva em informação. Esta nova forma de considerar os recursos faz parte da abordagem da Sociedade PósIndustrial, ponto de partida para se chegar à atual Sociedade da Informação, na qual conhecimento e capital intelectual são elementos fundamentais para o desenvolvimento de novos produtos e/ou serviços.

A partir deste novo contexto, a inovação passou a ter destaque para a estratégia das organizações. O trabalho colaborativo, por meio de parcerias e redes de colaboração, ganha destaque diante da necessidade de novas fontes de ideias e conhecimento. Esta é a abordagem defendida pelo modelo de Inovação Aberta sobre o aproveitamento de ideias, recursos e tecnologias disponíveis no ambiente externo.

A adoção do modelo de Inovação Aberta pelas organizações passa pelo desafio de superar o fator confiança para o estabelecimento de uma parceria. Embora muitos casos de sucesso evidenciam os benefícios do modelo aberto, a realidade ainda demonstra que algumas organizações não adotam o modelo devido à complexidade percebida na interação com parceiros externos.

Entre os fatores que podem representar complexidade destacam-se: o direito de Propriedade Intelectual, o sigilo das informações estratégicas, o alinhamento das expectativas (direitos e deveres) entre parceiros distintos, etc.

Além disso, é importante ressaltar a necessidade de desenvolvimento da estrutura interna da organização a fim de obter melhor performance na colaboração com seus parceiros, conforme constatado em estudos empíricos (CHESBROUGH, 2003; CHESBROUGH; CROWTHER, 2006; GASSMANN; ENKEL; CHESBROUGH, 2010; LAURSEN; SALTER, 2006; DITTRICH; DUYSTERS, 2007).

Os benefícios do modelo aberto foram analisados por vários estudos empíricos ao longo dos últimos anos (CHESBROUGH; CROWTHER, 2006; HUIZINGH, 2011; DAHLANDER; GANN, 2010; VANHAVERBEKE et al., 2012). Portanto, se o futuro parece estar pautado no ambiente colaborativo, torna-se importante criar condições que amenizam o clima de receio no uso e compartilhamento de informação entre parceiros no mesmo projeto.

A proposta de inserir a Gestão da Informação na abordagem da Inovação Aberta corrobora com a caracterização de organização inteligente realizada por Choo (2003). O autor descreve um ambiente 
onde estão presentes diversos intervenientes que colaboram e questionam-se uns aos outros, reconhecendo o caráter dinâmico e aberto das organizações.

Além disso, "à medida que o papel da informação dentro das empresas ficar mais claro, também teremos maior clareza sobre as condições, padrões e normas de utilização capazes de tornar a informação significativa e valiosa" (CHOO, 2006, p. 20). Quanto mais se conhecer sobre o uso da informação nas organizações, mais ações poderão ser empreendidas para discernir o que é relevante e pertinente.

Desse modo, será possível focar esforços e investimentos no que realmente contribui para os processos de Inovação Aberta e para a aquisição e manutenção de vantagens competitivas para a organização.

Diante do exposto, o presente estudo é classificado como exploratório e descritivo, pois embora já exista referencial teórico contemplado por diversos estudos empíricos (CHESBROUGH; CROWTHER, 2006; DAHLANDER; GANN, 2010; HUIZINGH, 2011; VANHAVERBEKE et al., 2012) sobre a adoção do modelo de Inovação Aberta, a integração direta do recurso "informação" neste âmbito pode ser considerada uma contribuição pertinente e atual tanto para o campo da Inovação como para a Ciência da Informação.

Este estudo teve como objetivo geral: identificar práticas de Inovação Aberta e ações de Gestão da Informação utilizadas pelas organizações no pólo tecnológico da cidade de Florianópolis, em Santa Catarina.

\section{0 modelo de inovação aberta}

O modelo de Inovação Aberta tem sido considerado o novo paradigma da gestão da inovação e sua característica de interação com o ambiente externo está diretamente relacionada à concepção das redes de colaboração.

A Inovação Aberta contrasta com os ideais defendidos até então no âmbito da gestão da inovação, sendo o paradigma anterior chamado de Inovação Fechada. Entre as razões para a alteração no modelo, até então predominante, está a dinâmica dos colaboradores entre empresas nas quais já atuaram. Isto porque, um colaborador quando sai de uma determinada instituição leva consigo o conhecimento adquirido na sua experiência de atuação.

Relacionado a este fato está o aumento do número de cursos de graduação e pós-graduação, bem como capacitações disponíveis presencialmente e online (CHESBROUGH, 2003). Além disso, a internet, proporcionando ferramentas de aprendizado e oportunidades de novos insights, marca este cenário dinâmico em que os colaboradores se inserem.

No modelo tradicional de inovação defendia-se que os melhores colaboradores do setor deveriam trabalhar na organização, enquanto no modelo de Inovação Aberta defende-se que é preciso ter os melhores 
colaboradores do setor trabalhando para a organização, sejam estes como colaboradores internos ou parceiros externos.

A rapidez no desenvolvimento e comercialização de novos produtos/serviços expõe as organizações ao desafio de buscar sempre novos conhecimentos. E este fato deixa evidente a dificuldade de posse de todos os atributos internamente.

A partir da contribuição de Chesbrough (2003), em sua obra intitulada Open Innovation: The New Imperative for Creating and Profiting from Technology, designou-se o modelo de Inovação Aberta, reunindo diversos aspectos já evidenciados em conceitos consolidados na literatura relacionada à gestão da inovação: ativos complementares (TEECE, 1986); fontes de conhecimento e inovação internas e externas (VON HIPPEL, 1986; NAPOLITANO, 1989); capacidade absortiva (COHEN; LEVINTHAL, 1989; 1990).

O conceito tem ganhado cada vez mais espaço nos estudos empíricos na literatura internacional e os resultados enfatizam os benefícios para empresas de diversos setores da economia. Após mais de uma década da formulação do modelo aberto, várias contribuições (CHESBROUGH, 2003; 2004; GANN, 2004; SMITH, 2004; HEMPHILL, 2005; BLAU, 2007; LEE et al., 2012) marcaram o entendimento e o estabelecimento deste conceito na literatura e prática de inovação.

Chesbrough e Bogers (2017, p. 42) trazem a definição da Inovação Aberta em uma perspectiva mais abrangente, definindo-a como "um processo de inovação distribuída com base nos fluxos intencionais de conhecimento gerenciados por toda a fronteira organizacional, utilizando mecanismos pecuniários e não pecuniários alinhados com o modelo de negócios da organização".

É interessante notar que nesta redefinição a afirmação de que o processo de Inovação Aberta deve alinhar-se ao modelo de negócio da organização aparece com mais ênfase nos ideais do conceito. Tendo em vista uma economia baseada em serviços, por exemplo, esta afirmação se torna coerente com a adaptação do cenário atual.

\subsection{Efeitos da inovação aberta: externalidades de rede e aprendizagem}

Ozman (2009) aponta que os benefícios da adoção de Inovação Aberta diferenciam-se consoante ao contexto de mercado, embora seja consensual que todas as indústrias possam se beneficiar.

Estes resultados podem ser caracterizados como efeitos de externalidades de rede e os efeitos de aprendizagem.

Os efeitos de externalidades de rede são, sobretudo, a redução de custos para o acesso dos diferentes usuários do grupo. Estes custos de acesso podem ser para o uso de determinada plataforma ou mesmo a licença e royalties.

Em mercados multilaterais os efeitos de externalidades de rede são mais acentuados. A oportunidade de redução de custos advindas do acesso a determinados padrões atrai potenciais parceiros de produtos 
complementares. Esta situação poderá resultar na percepção de valor pelos consumidores finais e pelos próprios fornecedores.

Além disto, Ozman (2009) também destaca que o envolvimento com as práticas de Inovação Aberta pode induzir mais aprendizado pelos stakeholders. Este fenômeno de aprendizagem, consequentemente, poderá contribuir para o aumento do nível de inovação da organização.

Estes efeitos proporcionados pela oportunidade de acesso às plataformas, licenças e royalties reforçam também o efeito de aprendizagem. Nas palavras de Ozman (2009, p. 8) "Quanto maior o número de atores envolvidos, maiores as chances de recombinar 0 conhecimento de vários atores, e maiores as chances de inovação".

O conceito de aprendizagem para inovação não é novo (Ozman, 2009). Este efeito no âmbito das práticas de Inovação Aberta tem significado aumento de interações entre os parceiros na forma de alianças estratégicas, colaboração em Pesquisa e Desenvolvimento (P\&D), joint ventures e equipes de desenvolvimento de produtos.

\section{Gestão da informação}

A informação tornou-se um importante ativo para as organizações, todavia, em alguns ambientes empresariais, ela ainda não é vista com o devido valor, tão pouco é gerida como outros recursos organizacionais.

Compreender seu papel no processo de inovação requer, anteriormente, o entendimento do que ela significa, diferenciando-a de outros termos. Por isso, é importante a conceitualização dos termos dado, informação e conhecimento.

Segundo Davenport (1998), dado compreende a simples observação da realidade, o estado dos fatos. Por não serem contextualizados, os dados podem ser facilmente estruturados, mensurados e transferidos, tanto entre pessoas quanto entre máquinas. Não há muito tratamento dos dados, estão disponibilizados de modo bruto até que provem a sua utilidade e propósito no contexto em causa.

A informação é o elo entre o dado e o conhecimento. Pode ser entendida como dados tratados, o que exige atuação humana como mediação interpretativa. De acordo com Drucker (1988, p. 46, tradução nossa), "informação são dados dotados de relevância e propósito", portanto, o capital humano é indispensável para a análise e o consenso sobre a aplicação em contextos específicos. Diferentemente dos dados, a informação é difícil de ser capturada, mensurada e transferida, por isso, ao longo de um processo de compartilhamento ela pode ser distorcida, mesmo que não intencionalmente.

Se a informação provém do dado, o conhecimento, por sua vez, pode ser entendido como o passo seguinte dessa sequência, pois é gerado a partir da informação. Ele é resultado de um processo de ressignificação e reflexão, a partir da obtenção de novas informações combinadas com conhecimentos anteriores já consolidados pelo indivíduo.

O controle sobre a informação, como elemento a ser gerenciado nas organizações, data do final do século XIX, com o surgimento de 
corporações altamente hierarquizadas e departamentalizadas, que necessitavam de coordenação e controle (BENIGER, 1986).

Conforme visto na definição dos conceitos, informação e conhecimento são difíceis de serem obtidos, estruturados, armazenados e transferidos através de máquinas, todavia, são essenciais para a sobrevivência e o desenvolvimento das empresas na Sociedade da Informação. Por isso, priorizar inadvertidamente os sistemas informacionais em detrimento da interação dos seres humanos com a informação e o conhecimento, não é uma postura adequada para os negócios (DAVENPORT, 1998).

As teorias e estudos sobre Gestão da Informação que se desenvolveram a partir da segunda metade do século $X X$ são mais amplas e abarcam vários processos. De acordo com Valentim (2004, p. 1), a Gestão da Informação compreende um

Conjunto de estratégias que visa identificar as necessidades informacionais, mapear os fluxos formais de informação nos diferentes ambientes da organização, assim como sua coleta, filtragem, análise, organização, armazenagem e disseminação, objetivando apoiar o desenvolvimento das atividades cotidianas e a tomada de decisão no ambiente corporativo.

Desse modo, a informação assume um papel de diferencial competitivo quando gerida adequadamente. De acordo com Choo (2006), ela perpassa todos os processos organizacionais e é utilizada em três arenas que compõem as organizações. Apesar de diferentes, esses três contextos se inter-relacionam e se complementam.

A primeira arena é a de criação de significado, na qual a organização utiliza a informação para compreender o que acontece no ambiente externo, de modo a se adaptar às constantes e repentinas mudanças do mercado dinâmico em que está inserida. A informação do ambiente externo pode estar relacionada a qualquer stakeholder, como clientes, fornecedores, governo e outros agentes que, em alguma medida, interferem diretamente ou influenciam as ações que a organização deve adotar. Na perspectiva de Davenport (1998, p. 248, grifos do autor), é possível a organização utilizar a informação do ambiente externo não apenas para se adequar ou responder a ele, como também para "moldar as condições exteriores, por meio de serviços e produtos da informação, visando a sua própria vantagem competitiva".

O segundo ambiente equivale à construção de conhecimento através do aprendizado. A informação é obtida, processada e compartilhada em interação com o conhecimento previamente adquirido pela organização. Esse movimento é capaz de gerar novas interpretações, insights, ideias e novos conhecimentos. Conforme descrito anteriormente, a aprendizagem organizacional influencia nos processos organizacionais, aperfeiçoando a maneira como as pessoas atuam e realizam suas entregas, e contribui para o desenvolvimento de inovações, tanto incrementais quanto radicais.

A terceira arena refere-se à tomada de decisão, um processo que deveria se basear na racionalidade. Todavia, no cotidiano das organizações, diversos são os fatores intervenientes, como informações 
insuficientes, conflitos de interesses e disputas de poder. Além disso, atualmente, as empresas também precisam lidar com a "sobrecarga de informações, e a organização destes fluxos é essencial para a competitividade da instituição, a questão central está em decifrar o valor estratégico da informação a fim de conseguir usá-la quando necessário" (PALETTA; SILVA; SANTOS, 2017, p. 8).

\subsection{O exercício de gerenciamento da informação}

A tomada de decisão é essencial, pois "toda ação da empresa é provocada por uma decisão, e toda decisão é um compromisso para uma ação" (CHOO, 2006, p. 29). Quanto mais informações pertinentes a organização possuir, e quanto mais hábil for para utilizá-las adequadamente, maiores as chances de que as decisões garantam a perpetuação e o progresso da empresa no mercado.

Davenport (1998) propõe um processo para gerenciamento da informação que contempla quatro passos, sendo eles a determinação das exigências da informação, a obtenção, a distribuição e o uso da informação.

Por sua vez, Choo (1995) estabelece um modelo semelhante, porém configurando-o em seis etapas, a saber, a identificação das necessidades de informação; a aquisição; a organização e o armazenamento; a criação de produtos e serviços de informação; a distribuição; e a utilização da informação.

As necessidades de informação devem ser identificadas abarcando não somente o que é preciso saber, como também a forma como o problema se manifesta, quais informações já estão disponíveis na organização sobre o assunto, quais serão as prováveis contribuições das informações a serem obtidas, como e em qual formato elas devem estar (CHOO, 2003) para serem melhor aproveitadas.

A aquisição é o segundo processo do modelo e também apresenta algumas complexidades. Na perspectiva de Choo (2003), além de se atentar para a concorrência e a clientela, atualmente as organizações devem também acompanhar tendências demográficas e econômicas, transições políticas e mudanças nas legislações, inovações tecnológicas, alterações no estilo de vida, dentre outros fatores. Diante de tantas informações, sobre tantos assuntos, é interessante que a organização selecione quais são as mais pertinentes às suas necessidades.

Com as informações obtidas, tem-se a etapa para organizá-las e armazená-las. A tecnologia da informação proporcionou grandes avanços nas últimas décadas, permitindo 0 armazenamento de grandes quantidades de dados em espaços cada vez menores. Todavia, é importante lembrar que as informações não estruturadas existem em maior quantidade do que as estruturadas, por isso "a organização deve estabelecer uma gestão de registros e uma política de arquivo integradas de forma a permitir-se criar, preservar e potencializar a sua memória corporativa" (CHOO, 2003, p. 71). 
A etapa seguinte refere-se à criação e ao desenvolvimento de produtos e serviços de informação, para que a organização tenha acesso a informações de alta qualidade através de diferentes meios. Esses caminhos devem oferecer informações que respondam às necessidades de informação e que possibilitem a solução dos problemas. Devem estar orientadas para a ação e ter como principais características a facilidade de utilização, a redução de ruído, a qualidade, a adaptabilidade e a economia de tempo e de custos.

A distribuição de informação compreende o compartilhamento das informações que a organização possui. Ela deve acontecer em consonância com os hábitos e as preferências dos utilizadores, o que não significa que a organização precisará personalizar a difusão para cada colaborador. O importante é que haja diferentes meios de partilha, que se adequem aos diferentes perfis existentes na empresa, levando-se em conta, principalmente, a facilidade de utilização e a acessibilidade física dos instrumentos de disseminação ( $\mathrm{CHOO}, 2003)$. Além disso, os usuários das informações devem ser considerados agentes ativos no processo, de modo que também possam buscar o que consideram pertinente à sua atuação na empresa.

A sexta e última etapa contempla a utilização da informação. Conforme mencionado anteriormente, a informação é usada em três diferentes e complementares contextos, para compreensão do ambiente e criação de sentido, para construção de conhecimento e para tomada de decisões.

Dessa maneira, as organizações que conseguem gerir a informação, utilizando-a eficazmente para compreender o ambiente, gerar novos conhecimentos e tomar decisões, valendo-se dos processos de gerenciamento mencionados, tendem a possuir vantagens competitivas que garantem a sobrevivência e promovem o crescimento, apesar das possíveis adversidades existentes no mercado.

\section{Procedimentos metodológicos}

A presente pesquisa caracteriza-se como exploratória e descritiva, pois pretende aproximar temáticas de conhecimento de forma integrada por meio da análise da adoção de suas práticas: Gestão da Informação e Inovação Aberta.

Para atender o objetivo do estudo, aplicou-se um questionário com perguntas abertas e fechadas, de cunho qualitativo, enviado via Google Forms durante os meses de março a junho de 2018.

A construção do instrumento de coleta de dados (questionário) teve como base o aporte teórico apresentado em seções anteriores e que se encontra sintetizada no quadro a seguir: 
Quadro 1 - Suporte teórico na construção do instrumento de coleta de dados

\begin{tabular}{l|l|l}
\hline \multicolumn{1}{c|}{ Temáticas } & \multicolumn{1}{c}{ Aspectos analisados } & \multicolumn{1}{c}{ Referências } \\
\hline 1. Práticas de Inovação Aberta & $\begin{array}{l}\text { - Características das práticas (tipos de parceiros, } \\
\text { dimensões de abertura) } \\
\text { - Efeitos de adoção: externalidades de rede e de } \\
\text { aprendizagem }\end{array}$ & $\begin{array}{l}\text { Chesbrough (2003) Chesbrough e } \\
\text { Brunswicker (2013) } \\
\text { Ozman (2009) }\end{array}$ \\
\hline $\begin{array}{l}\text { 2. Fatores internos com efeitos } \\
\text { na vantagem competitiva }\end{array}$ & $\begin{array}{l}\text { - Aprendizagem organizacional } \\
\text { - Memória organizacional }\end{array}$ & $\begin{array}{l}\text { Camisón e Villar-López (2011) } \\
\text { Cohen e Levinthal (1989; 1990) }\end{array}$ \\
\hline 3. Gestão da Informação & $\begin{array}{l}\text { - Práticas de Gestão da Informação } \\
\text { - Aspectos motivacionais }\end{array}$ & $\begin{array}{l}\text { Choo (2006) } \\
\text { Hwang, Kettinger e Yi (2013) }\end{array}$ \\
\hline $\begin{array}{l}\text { 4. Caracterização da } \\
\text { organização }\end{array}$ & Número de colaboradores, setor de atuação, faturamento, indicadores de inovação. \\
\hline
\end{tabular}

Fonte: Dados da pesquisa.

Para identificação do universo da pesquisa, foi realizado um levantamento das empresas sediadas em Florianópolis que atuam no polo de tecnologia e inovação. Por meio da Associação Catarinense de Tecnologia (ACATE) e da Fundação Centros de Referência em Tecnologias Inovadoras (CERTI), foi possível obter uma relação de organizações atuantes na ilha de Santa Catarina, com as quais foi feito contato por email e/ou telefone para sensibilização à participação na pesquisa.

A amostra contou com a participação de nove empresas do setor de software e os respondentes ocupam cargos que permitem uma visão sistêmica da organização, ponto importante para que o questionário pudesse ser respondido com maior precisão. Entre o cargo/função dos respondentes, destacam-se: analista de dados, co-fundador/CEO, diretor administrativo, gestor e coordenador.

Ressalta-se que este estudo poderá ser posteriormente ampliado para outros polos tecnológicos, bem como uma nova versão para o mesmo universo da pesquisa no sentido de alargar a amostra de participações.

\subsection{Do campo de análise: pólo tecnológico de Florianópolis}

Esta subseção sintetiza informações sobre o polo tecnológico de Florianópolis com o intuito de justificar a escolha deste contexto como campo de análise para este estudo, que posteriormente poderá ser replicado em outras regiões e polos tecnológicos.

Florianópolis está localizada no estado de Santa Catarina, região sul do Brasil, e possui aproximadamente 485 mil habitantes (INSTITUTO BRASILEIRO DE GEOGRAFIA E ESTATÍSTICA - IBGE, 2017). A cidade é 
conhecida por suas paisagens naturais e pela qualidade de vida que proporciona aos seus moradores. Com um Índice de Desenvolvimento Humano Municipal de 0,847, acima da média brasileira (IBGE, 2017), atrai pessoas de outras cidades, estados e países.

Mesmo sendo a capital do estado, limitações geográficas e legislações ambientais inviabilizam a instalação de grandes indústrias. Em contrapartida, as características da ilha fazem com que ela tenha uma vocação natural para o turismo, tendo emergido no cenário nacional como destino turístico na década de 1980 (CANELLA, 2015), graças a decisões políticas e econômicas que foram tomadas desde os anos 1950.

Entretanto, nos últimos anos, Florianópolis tem se destacado em outros cenários. A partir de 2014, a Endeavor tem conduzido uma pesquisa anual denominada Índice de Cidades Empreendedoras (ENDEAVOR, 2018), cujos pilares são o ambiente regulatório, a infraestrutura, o mercado, o acesso a capital, a inovação, o capital humano e a cultura empreendedora. Na primeira edição da pesquisa, Florianópolis ficou na primeira posição, sendo chamada de ilha empreendedora e destacando-se no cenário nacional como um local propício à abertura e condução de novos negócios. Nas edições de 2015 a 2017, permaneceu em segundo lugar no ranking, atrás apenas de São Paulo.

Especificamente no pilar inovação, Florianópolis esteve no primeiro lugar nos anos de 2014 e 2015, ocupando o segundo lugar em 2016 e o terceiro em 2017. Todavia, permaneceu a primeira no critério que considera a proporção de mestres e doutores em Ciência e Tecnologia por empresa, com uma média de 20 profissionais com tais titulações para cada 100 empresas. De acordo com a edição de 2016, essa característica contribui para que a cidade tenha o segundo maior número de empresas atuantes em Tecnologias da Informação e Comunicação.

No pilar capital humano, Florianópolis manteve o primeiro lugar em todas as edições da pesquisa, com destaque para os índices relativos ao acesso e à qualidade da mão de obra qualificada (ENDEAVOR, 2018), em consonância com os dados supracitados.

O município também conta com legislação que trata especificamente de tecnologia e inovação. Em 2017 foi publicado o Decreto no 17.097 (FLORIANÓPOLIS, 2017a) que regulamentou a Lei Complementar no 432, de 2012, que "dispõe sobre sistemas, mecanismos e incentivos à atividade tecnológica e inovativa, visando o desenvolvimento sustentável do município de Florianópolis" (FLORIANÓPOLIS, 2012).

Em 1984 foi criado o Centro Regional de Tecnologia em Informática, proveniente do Departamento de Engenharia Mecânica da UFSC. Em 1994 passou a ser denominado Fundação Centros de Referência em Tecnologia Inovadora (CERTI), caracterizando-se como uma instituição independente e sem fins lucrativos cujo objetivo é fornecer soluções inovadoras para o governo, as organizações privadas e o terceiro setor (CERTI, 2018).

Dois anos depois dava origem à Incubadora Empresarial Tecnológica, posteriormente denominada Centro Empresarial para Laboração de Tecnologias Avançadas (CELTA). O CELTA foi uma das 
primeiras incubadoras do país, sempre incentivando e apoiando a abertura de novas empresas, oferecendo suporte a empreendimentos de base tecnológica.

Em 1986 foi inaugurada a Associação Catarinense de Empresas de Tecnologia (ACATE), que se tornou um importante interlocutor entre as empresas de tecnologia do estado e outros agentes, como o poder público, entidades representativas e instituições do setor tecnológico, além de atuar na articulação entre o setor tecnológico, os centros de ensino e pesquisa e as agências financiadoras. Em 2015 a ACATE inaugurou seu Centro de Inovação, que além de algumas das associadas, ainda abriga coworking e aceleradora. Dois anos mais tarde, foi criado o $L i n k L a b$, espaço colaborativo que aproxima startups e empresas já consolidadas no mercado, proporcionando a troca de saberes e o desenvolvimento de soluções inovadoras para os negócios.

Em 1998 uma parceria entre a ACATE e o Serviço Brasileiro de Apoio às Micro e Pequenas Empresas de Santa Catarina (SEBRAE/SC) deu origem ao Micro Distrito Industrial Tecnológico (MIDITEC), uma incubadora que se tornou referência nacional de modelo de incubação e, assim como o CELTA, recebeu prêmios Anprotec de Melhor Incubadora em diferentes categorias entre os anos de 2008 e 2016 (MIDITEC, 2018). Em fevereiro de 2018 o MIDITEC foi eleito pela UBI Global a quinta melhor incubadora de negócios do mundo na categoria Colaboração com Universidade, ratificando os bons resultados que a instituição tem obtido desde seu surgimento.

Em 2001 teve início o projeto do Sapiens Parque, a partir de um Acordo de Cooperação firmado entre o governo estadual e a Fundação CERTI. Nos anos seguintes foi aprovada a viabilização urbanística e ambiental e, em 2006, foi inaugurado o marco zero (AZEVEDO; TEIXEIRA, 2017). O Sapiens Parque é um parque de inovação que disponibiliza infraestrutura para a instalação de empresas (SAPIENS PARQUE, 2018), buscando integrar as iniciativas existentes em seu ambiente para proporcionar o desenvolvimento dos negócios e da sociedade.

Outro pioneirismo da ilha de Santa Catarina no que tange à inovação foi a implantação do primeiro coworking do setor público, o WeGov, um espaço de aprendizagem com o propósito de difundir a cultura de inovação neste setor (WEGOV, 2018).

Uma das iniciativas mais recentes foi a Portaria no 18/SMTTDE CTI/2017, que institui normas para o Programa de Incentivo à Inovação, que tem como objetivo...

[...] promover o empreendedorismo inovador por meio de concessão de incentivo fiscal ao contribuinte incentivador, tanto pessoa física quanto pessoa jurídica, estabelecido no Município de Florianópolis, que contribuir financeiramente em projetos de inovação. (FLORIANÓPOLIS, 2017b).

Diante do exposto, percebe-se o crescimento e o progresso de Florianópolis como um polo tecnológico e inovador, conectado ao restante 
do Brasil e ao mundo, com condições favoráveis ao desenvolvimento de carreiras e negócios em inovação e tecnologia.

\section{Práticas de gestão da informação e inovação aberta}

As nove empresas participantes do estudo são relativamente recentes, $44 \%$ estão no mercado há menos de 5 anos e $33 \%$ atuam entre 5 e 10 anos. Quanto ao número de colaboradores, 44\% possuem até 19 colaboradores, enquanto $33 \%$ atuam com um quadro de 20 a 99 colaboradores e $22 \%$ empregam mais de 100 colaboradores.

Apenas $11 \%$ das empresas participantes afirmam não possuir qualquer prática que possa ser considerada de Gestão da Informação, enquanto as demais explicitam algumas ferramentas utilizadas para lidar com a informação existente na empresa. Todavia, em outra seção do questionário, quando indagadas sobre a existência de procedimentos formais de Gestão da Informação, 33\% das empresas afirmam não possuí-los. As demais afirmam que possuem esta gestão formalizada, porém sem detalhar os procedimentos adotados. Uma delas especifica o nome de um ambiente virtual adotado, mas que remete ao gerenciamento de dados, não de informação.

Considerando as três arenas estabelecidas por Choo (2006), a maioria das respondentes $(78 \%)$, afirmam que utilizam a informação tanto para gerar novos conhecimentos quanto para tomar decisões, enquanto a compreensão das mudanças do ambiente externo é ressaltada por $56 \%$ dos participantes. Interessante observar que $11 \%$ afirmam não utilizar a informação, demonstrando que, em alguns casos, ela não é sequer percebida como um ativo da empresa.

A informação é maioritariamente obtida por meio de mídias digitais (para $89 \%$ dos respondentes) e em eventos promovidos por entidades do próprio setor de atuação (para $78 \%$ dos respondentes). Outras fontes de informação são grupos de trabalho com representantes do próprio setor $(44 \%)$, assim como eventos (33\%) e grupos de trabalhos (33\%) de organizações de segmentos distintos.

A captação de informações no ambiente externo é feita para conhecer mais sobre o negócio (67\% das empresas participantes), tendo em vista novas oportunidades e tendências, assim como concorrentes e mercado consumidor, há também empresas que buscam informações sobre qualidade dos próprios produtos (11\%), inovação (11\%) e mudanças na legislação pertinente ao segmento de atuação (11\%).

Os colaboradores são estimulados à aquisição de informações, principalmente, por meio de networking (78\% das empresas respondentes). Também são incentivadas as redes de colaboração e o contato com parceiros (56\%), treinamentos técnicos $(44 \%)$, eventos setoriais (33\%) e comunidades de práticas (33\%). Apenas 11\% responderam que a obtenção de informações não é diretamente estimulada pela organização.

A maioria das empresas (78\%) não possui uma área específica para a análise de informações, sendo que uma delas explica que a função de 
análise é realizada informalmente, em especial, pelos sócios. Para as demais, não há uma denominação comum e as análises são feitas nas áreas de Produto, de Marketing ou de Data Analytics e Business Intelligence.

Visto que a maioria das empresas não possui área específica de Gestão da Informação, também não há profissionais dedicados exclusivamente à análise de informações. Para as que possuem, as formações dos profissionais contemplam as graduações de Sistemas de Informação, Ciência da Computação, Administração e Engenharias.

A informação é avaliada em $67 \%$ das empresas respondentes, porém, por meio de diferentes práticas, por exemplo, desde reuniões com os envolvidos até procedimentos de machine learning, demonstrando a ausência de metodologia padronizada.

Choo (2006) não estabelece uma etapa específica para o descarte de informações, todavia, foi questionado às empresas se há procedimentos que determinam os critérios para armazenamento, manutenção e eliminação de informações na organização. Das empresas participantes, $22 \%$ responderam que tais procedimentos não existem, $22 \%$ afirmam que há procedimentos padrão, mas que não são formalizados, 33\% apontam que apesar de formalizados, os procedimentos nem sempre são seguidos, enquanto outros $22 \%$ asseguram que, além de formalizados, os procedimentos são devidamente seguidos pelos colaboradores.

Em 56\% dos participantes, as informações são arquivadas em nuvem, em servidores que disponibilizam armazenamento com versões gratuitas e pagas, ademais, arquivos salvos são nomeados seguindo padrões determinados pela empresa, a fim de facilitar a futura recuperação. Dos $44 \%$ restantes, 33\% não especificaram suas práticas e $11 \%$ afirmaram que não existem procedimentos específicos para a etapa de organização e armazenamento da informação, conforme a terceira etapa do modelo de Gestão da Informação proposto por Choo (2006).

O compartilhamento de informação é realizado (internamente e por $67 \%$ dos respondentes) por meio dos softwares mencionados, nos quais as informações são armazenadas, assim como por meio de outras mídias digitais e analógicas que circulam na organização. Em 33\% das empresas estudadas, há também práticas de reuniões, workshops e treinamentos com diversas periodicidades, como semanais, mensais e trimestrais. Interessante observar que uma empresa participante do estudo afirma estimular a busca de informações por parte dos colaboradores, ratificando a perspectiva de Choo (2003, p. 84) que afirma que se deve admitir "os próprios utilizadores na rede de distribuição como participantes ativos e colaborativos".

Outro ponto a ser destacado é a utilização de informações formais da empresa, pois na maioria das organizações participantes $(67 \%)$, elas tendem a ser preteridas em detrimento das informações informais.

Como pode ser observado, a maneira de lidar com a informação varia de acordo com a empresa. As relações que os colaboradores estabelecem com tal ativo estão sintetizadas no Gráfico 1. 
Gráfico 1 - Atitudes dos colaboradores nas empresas pesquisadas

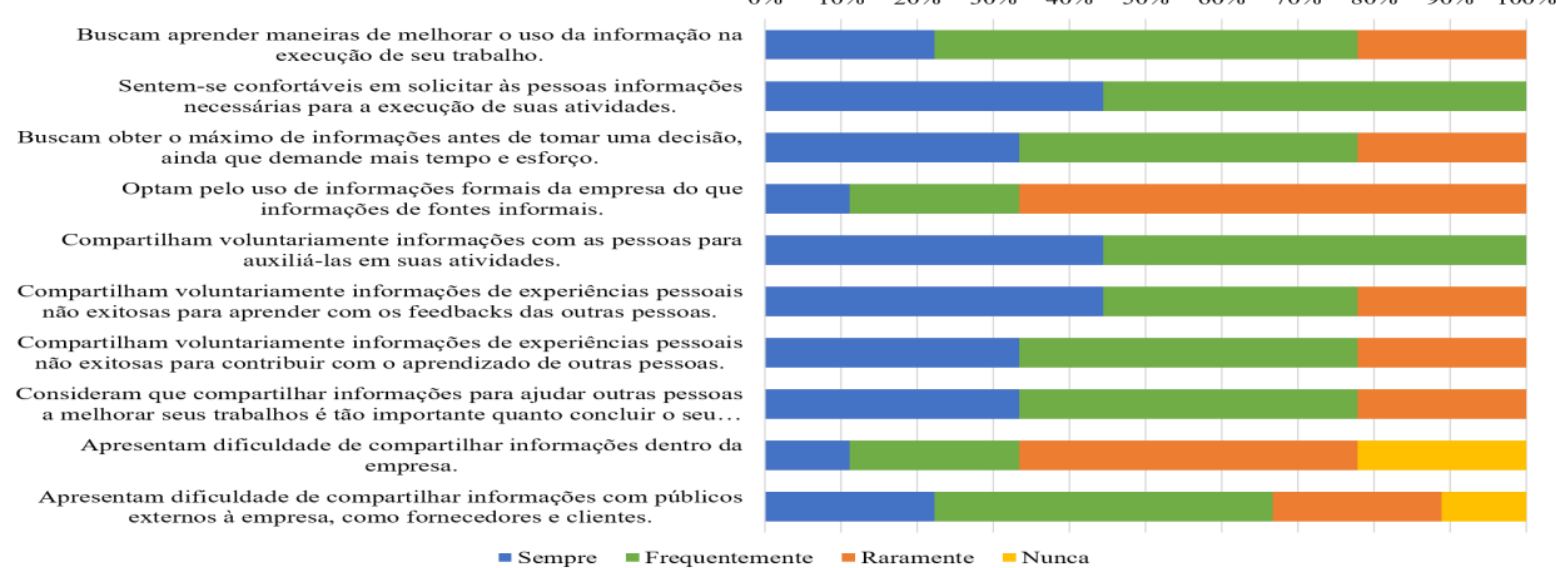

Fonte: Dados da pesquisa.

Com relação às práticas de Inovação Aberta, os resultados corroboram com a necessidade de suporte para a disseminação da adoção do modelo de forma mais ampla. Conforme se observa no Gráfico 2, a importância das práticas de Inovação Aberta nos últimos 3 anos é, sobretudo, percebida na venda de produtos ao mercado, seguida das atividades de redes informais, networking informal e cocriação com clientes e consumidores.

No entanto, várias práticas de Inovação Aberta ainda não têm sido utilizadas em período recente pelas empresas entrevistadas. Dentre elas, spin-offs, consórcio de P\&D com apoio de fundos públicos, comercialização de propriedade intelectual e crowdsourcing para a resolução de problemas reais.

Gráfico 2 - Importância das Práticas de Inovação Aberta

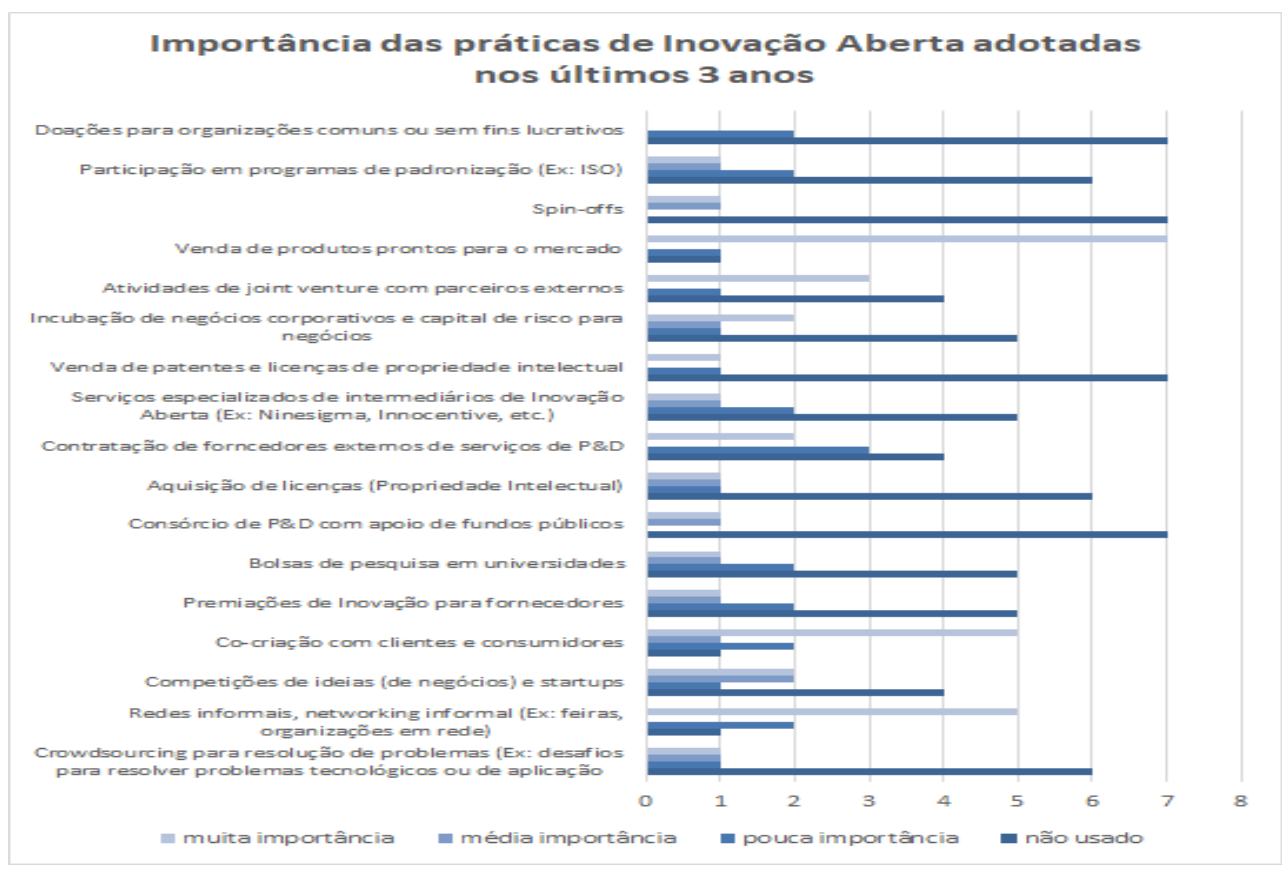


Fonte: Dados da pesquisa.

Com relação ao tipo de parceiro e o grau de importância atribuído a esta parceria, houve participação de alguns stakeholders específicos nas atividades colaborativas das empresas entrevistadas. Entre os três parceiros mais importantes nas práticas de Inovação Aberta estão: os colaboradores, os consumidores finais e os fornecedores.

Assim como apontado por Chesbrough (2003), os fornecedores ampliaram suas capacidades e tornaram-se relevantes também no processo criativo das organizações, oferecendo ideias, novos tipos de materiais, etc.

Por outro lado, os considerados menos importantes ou sequer utilizados foram as universidades e as organizações públicas de pesquisa.

Isso demonstra o quanto o mercado, por vezes, ainda é avesso à parceria com tais entidades, não pela falta de qualificação ou de aplicabilidade do que tem sido desenvolvido no ambiente acadêmico e de pesquisa. Mas sim, pelas disparidades existentes nos processos decisórios das instituições públicas e privadas, fazendo com que o ritmo dos acontecimentos no público não seja aplicável às demandas do privado.

Gráfico 3 - Importância dos parceiros nas práticas de Inovação Aberta

\section{Importância dos parceiros nas práticas de Inovação Aberta}

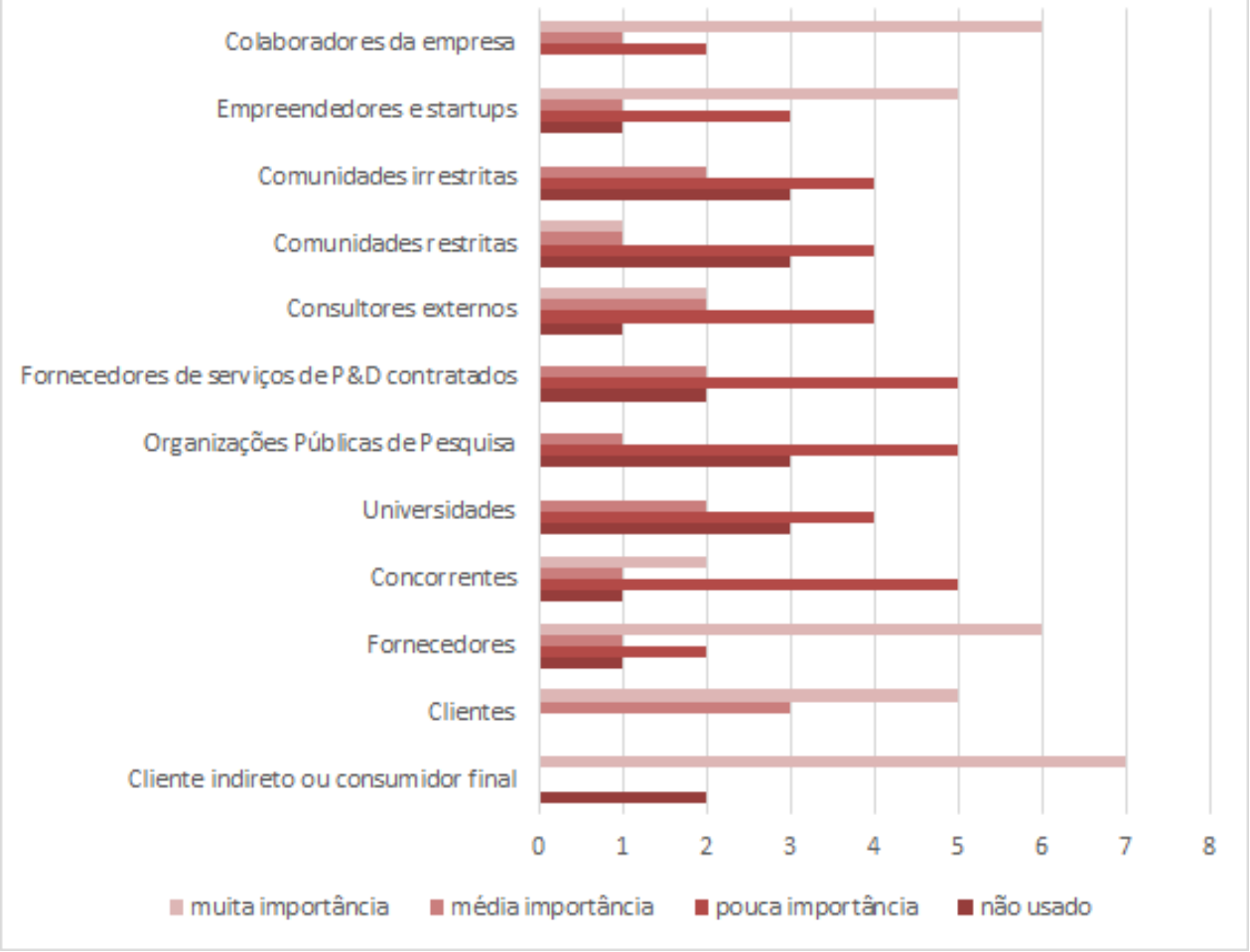

Fonte: Dados da pesquisa.

O que mais motiva as organizações a investirem em inovação é a necessidade de se manterem à frente dos concorrentes, assim como a redução de custos e o aumento do valor percebido pelos clientes. 
Além disso, corroborando a afirmação de Ozman (2009), o investimento em inovação também induz mais aprendizados aos envolvidos, pois o conhecimento pode ser recombinado entre os profissionais, e proporciona maior articulação das equipes de desenvolvimento de produtos e serviços, podendo resultar em mais inovação.

\section{Considerações finais}

Os estudos de gestão estratégica da informação existem há cerca de três décadas. Todavia, as organizações parecem não atribuir o devido valor ao recurso informacional, mesmo ele tendo se tornado um importante ativo no ambiente corporativo.

Esta constatação corrobora com a evidência desta pesquisa de que, as organizações possuem alguns procedimentos informalmente padronizados para lidar com a informação, entretanto, não existem setores e profissionais dedicados exclusivamente à sua gestão.

A inovação, por sua vez, quando realizada com a contribuição de agentes externos, conta principalmente com colaboradores, consumidores finais e fornecedores. Outros atores, como organizações públicas de pesquisa e universidades, sequer são colocados no papel de parceiro por algumas das empresas pesquisadas.

Além disso, é notória a ausência de estratégias e de documentação referente à Inovação Aberta. Prejuízos podem ser causados, como a desconfiança na interação com outros atores do ambiente, falta de clareza da postura que os profissionais internos devem adotar na condução e/ou participação em processos colaborativos de inovação, vazamento de informações internas que não deveriam ser compartilhadas, colocando a organização em uma situação de vulnerabilidade no mercado e assim por diante.

Ainda que Florianópolis tenha se tornado uma referência em empreendedorismo, tecnologia e inovação é importante frisar que as organizações locais poderiam ter melhor desempenho se a informação fosse gerida de maneira estratégica e integrada à inovação. Se os atores envolvidos possuíssem estratégias que orientassem os processos colaborativos, por meio de práticas de Inovação Aberta, atuando com transparência e objetivando o ganho coletivo, produtos e serviços seriam criados e aperfeiçoados de maneira mais eficaz.

A limitação da pesquisa é a amostra alcançada nesta fase de aplicação, considerando uma amostra específica. Todavia, ela poderá ser ampliada em estudos empíricos futuros, a fim de que a investigação com outras organizações e polos tecnológicos possa proporcionar um cenário mais amplo relativo às temáticas estudadas $e$, consequentemente, possibilite posteriores exercícios comparativos.

\section{Referências}


ASSOCIAÇÃO CATARINENSE DE TECNOLOGIA (ACATE). Institucional. Florianópolis: ACATE, $2018 . \quad$ Disponível em: <https://www.acate.com.br/historico>. Acesso em: 3 jul. 2018.

AZEVEDO, I. S. C. de; TEIXEIRA, C. S. Florianópolis: uma análise evolutiva do desenvolvimento inovador da cidade a partir do seu ecossistema de inovação. Revista Eletrônica do Alto Vale do Itajaí, v. 6, n. 9, p. 108-121, jul. 2017.

BENIGER, J. R. The control revolution: technological and economic origins of the information society. Cambridge: Harvard University Press, 1986.

BLAU, J. Philips tears down Eindhoven R\&D fence. Research Technology Management, v. 50, n. 6, p. 9-10, 2007.

CAMISÓN, C.; VILLAR-LÓPEZ, A. Non-technical innovation: Organizational memory and learning capabilities as antecedent factors with effects on sustained competitive advantage. Industrial Marketing Management, v. 40, p. 1294-1304, 2011.

CANELLA, F. Cidade turística, cidade de migrantes: movimento dos semteto e representações sociais em Florianópolis (1989-2015). Revista Libertas, Juiz de Fora, v. 15, n. 2, p. 215-242, ago./dez. 2015.

CENTRO EMPRESARIAL PARA LABORAÇÃO DE TECNOLOGIAS AVANÇADAS (CELTA). Histórico. Florianópolis: CELTA, 2018. Disponível em: <http://www.celta.org.br/historico.html>. Acesso em: 3 jul. 2018.

CENTROS DE REFERÊNCIA EM TECNOLOGIAS INOVADORAS (CERTI). $A$ Fundação CERTI: institucional. Florianópolis: CERTI, 2018. Disponível em: <http://www.certi.org.br/pt/acerti>. Acesso em: 3 jul. 2018.

$\mathrm{CHESBROUGH}, \mathrm{H}$. Open innovation: the new imperative for creating and profiting from technology. Boston: Harvard Business School Press, p. 5978, 2003.

CHESBROUGH, $\mathrm{H}$. Managing open innovation. Industrial Research Institute, v. 47, p. 23-26, 2004.

CHESBROUGH, H.; BOGERS, M. Explicando a inovação aberta: esclarecendo esse paradigma emergente para 0 entendimento da inovação. In: CHESBROUGH, H.; VANHAVERBEKE, W.; WEST, J. (Orgs.). Novas fronteiras em inovação aberta. São Paulo: Blucher, 2017. p. 27-53.

CHESBROUGH, H.; BRUNSWICKER, S. Managing open innovation in large firm: survey report. Califórnia: UC Berkeley;Stuttgart: Fraunhofer Institute for Industrial Engineering, 2013. Disponível em: <http://openinnovation.gv.at/wp-content/uploads/2015/08/Fraunhofer2013-studie_managing_open-innovation.pdf >. Acesso em: 8 out. 2017.

CHESBROUGH, H.; CROWTHER, A. K. Beyond high tech: early adopters of open innovation in other industries. R\&D Management, v. $36, \mathrm{n} .3, \mathrm{p} .229$ 236, 2006. 
$\mathrm{CHOO}, \mathrm{C} . \mathrm{W}$. Information management for the intelligent organization: roles and implication for the information professions. Digital Libraries Conference. Singapore: National Computer Board of Singapore, 1995. Disponível em: <http://choo.fis.utoronto.ca/fis/respub/dlc95.html>. Acesso em: 8 out. 2017.

CHOO, C. W. Gestão de informação para a organização inteligente: a arte de explorar o meio ambiente. Lisboa: Editorial Caminho, 2003.

CHOO, C. W. A organização do conhecimento: como as organizações usam a informação para criar significado, construir conhecimento e tomar decisões. 2. ed. São Paulo: Editora Senac São Paulo, 2006.

COHEN, W.M.; LEVINTHAL, D.A. Innovation and learning: two faces of R\&D. The Economic Journal, v. 99, p. 569-596, 1989.

COHEN, W.M.; LEVINTHAL, D.A. Absorptive capacity: a new perspective on learning and innovation. Administrative Science Quarterly, v. 35, n. 1, p. 128-152, 1990.

DAHLANDER, L.; GANN, D. How open is innovation? Research Policy, v. 39, p. 699-709, 2010.

DAVENPORT, T. H. Ecologia da informação: por que só a tecnologia não basta para o sucesso na era da informação. São Paulo: Futura, 1998.

DITTRICH, K.; DUYSTERS, G. Networking as a means to strategy change: the case of open innovation in mobile telephony. The Journal of Product Innovation Management, v. 24, p. 510- 521, 2007.

DRUCKER, P. The coming of the new organization. Harvard Business Review, 66, p. 45-53, jan./fev. 1988. Disponível em: <https://hbr.org/1988/01/the-coming-of-the-new-organization>. Acesso em: 5 abr. 2018.

ENDEAVOR. Índice de Cidades Empreendedoras. São Paulo: Endeavor, 2018. Disponível em: <https://endeavor.org.br/pesquisas/>. Acesso em: 1 jul. 2018.

FLORIANÓPOLIS. Lei complementar no 432, de 7 de maio de 2012. Dispõe sobre sistemas, mecanismos e incentivos à atividade tecnológica e inovativa, visando o desenvolvimento sustentável do município de Florianópolis. Diário Oficial do Município de Florianópolis, n. 716, Florianópolis, SC, 7 maio 2012. Disponível em: <http://www.cmf.sc.gov.br/legislacao>. Acesso em: 2 jul. 2018.

FLORIANÓPOLIS. Decreto no 17.097, de 27 de janeiro de 2017. Regulamenta a Lei Complementar no 432, de 2012, que dispõe sobre sistemas, mecanismos e incentivos à atividade tecnológica e inovativa, visando o desenvolvimento sustentável do município de Florianópolis e estabelece outras providências. Diário Oficial Eletrônico do Município de Florianópolis, n. 1872, Florianópolis, SC, 27 jan. 2017a. Disponível em: <http://www.cmf.sc.gov.br/legislacao>. Acesso em: 2 jul. 2018. 
FLORIANÓPOLIS. Portaria no 18/SMTTDE, de 21 de novembro de 2017. Institui normas complementares para o programa de incentivo fiscal à inovação em Florianópolis. Diário Oficial Eletrônico do Município de Florianópolis, n. 2071, Florianópolis, SC, 21 nov. 2017b. Disponível em: <http://www.pmf.sc.gov.br/arquivos/diario/pdf/21_11_2017_20.19.42.a6 45fdcf908fc61fbe46074672234cb9.pdf>. Acesso em: 2 jul. 2018.

FLORIANÓPOLIS. Polo tecnológico. Florianópolis: SMTTDE, 2018.

Disponível

em:

<http://www.pmf.sc.gov.br/entidades/turismo/index.php?cms=polo+tecn ologico\&menu=11\&submenuid=1733>. Acesso em: 2 jul. 2018.

GANN, D. Book review - open innovation: the new imperative for creating and profiting from technology. Research Policy, v. 10, n. 1, p. 122-123, 2004.

GASSMANN, O.; ENKEL, E.; CHESBROUGH, H. The future of open innovation. R\&D Management, v. 40, n. 3, p. 213-221, jun. 2010.

HEMPHILL, T. Book review - Open innovation: the new imperative for creating and profiting from technology. Academy of Management Executive, v. 19, p. 164-165, 2005.

HUIZINGH, E. K. R. E. Open innovation: state of the art and future perspectives. Technovation, v. 31, n. 1, p. 2-9, 2011.

HWANG, Y.; KETTINGER, W. J.; YI, M. Y. A study on the motivational aspects of information management practice. International Journal of Information Management, v. 33, p. 177-184, 2013.

INSTITUTO BRASILEIRO DE GEOGRAFIA E ESTATÍSTICA (IBGE). Florianópolis. Brasília, DF: IBGE, 2017. Disponível em: <https://cidades.ibge.gov.br/brasil/sc/florianopolis/panorama $>$. Acesso em: 1 jul. 2018.

LAURSEN, K.; SALTER, A. Open for innovation: the role of openness in explaining innovation performance among UK manufacturing firms. Strategic Management Journal, v. 27, p. 131-150, 2006.

LEE, S. et al. Open innovation in SMEs: an intermediated network model. Research Policy, v. 39, n. 2, p. 290-300, 2010.

MIDITEC. MIDI Tecnológico. Florianópolis: MIDITEC, 2018. Disponível em: <http://www.miditecnologico.com.br/quem-somos>. Acesso em: 3 jul. 2018.

NAPOLITANO, G. Industrial research and sources of innovation: a crossindustry analysis of the Italian manufacturing firms. Columbia University, 1989.

OZMAN, M. Inter-firm networks and innovation: a survey of literature. Economic of Innovation and New Technology, v. 18, n. 1, p. 39-67, 2009.

ALETTA, F. C.; SILVA, L. G.; SANTOS, T. Informação empresarial: conceitos de relevância e pertinência aplicados a mídias sociais. Revista 
Brasileira de Biblioteconomia e Documentação, v. 13, n. 1, p. 2-14, 2017. Disponível em: <https://rbbd.febab.org.br/rbbd/article/view/429/584>. Acesso em: 26 fev. 2018.

SAPIENS PARQUE. Sobre o Sapiens. Florianópolis: Sapiens Parque, 2018. Disponível em: <http://www.sapiensparque.com.br/sobre/>. Acesso em: 4 jul. 2018.

SMITH, P. Book review- open innovation: the open innovation: the new imperative for creating and profiting from technology. Journal of Product Innovation Management, v. 21, p. 221-224, 2004.

TEECE, D. J. Profiting from technological innovation: implications for integration collaboration, licensing and public policy. Research Policy, v. 15 , p. 285-305, 1986.

VALENTIM, M. L. P. Gestão da informação e gestão do conhecimento: especificidades e convergências. [s.l.]: INFOHome, 2004. Disponível em: <https://www.ofaj.com.br/colunas_conteudo.php?cod=88>. Acesso em: 29 mai. 2018.

VANHAVERBEKE, W.; VERMEERSCH, I.; ZUTTER, S. Open Innovation in SMEs: how can small companies and start-ups benefit from open innovation strategies? Research Report, 2012.

VON HIPPEL, E. Lead users: a source of novel products concepts. Management Science, v. 32, p. 791-805, 1986.

WEGOV. Quem somos. Florianópolis: WeGov, 2018. Disponível em: <http://www.wegov.net.br/equipe/>. Acesso em: 4 jul. 2018. 